\title{
Callosal Atrophy Correlates with Temporal Lobe Volume and Mental Status in Alzheimer's Disease
}

\author{
Sandra E. Black, Scott D. Moffat, David C. Yu, Jayson Parker, Peter Stanchev, \\ Michael Bronskill
}

\begin{abstract}
Background: Recent studies have reported significant atrophy of the corpus callosum (CC) in Alzheimer's Disease (AD). However, it is currently unknown whether CC atrophy is associated with specific cortical volume changes in AD. Moreover, possible atrophy in extra-callosal commissures has not been examined to date. The purpose of the present study was to quantify atrophy in two cerebral commissures [the $\mathrm{CC}$ and the anterior commissure (AC)], to correlate this measure with cognitive status, and to relate commissural size to independent measures of temporal lobe volume in AD patients. Methods: A sample of AD patients and of age- and education-matched normal control subjects (NCs) underwent MRI and a cognitive test battery including the Dementia Rating Scale and Mini Mental State examination. Mid-sagittal regional areas within CC and AC were measured along with superior, middle and inferior temporal lobes volumes. Results: Alzheimer's Disease patients had significantly smaller callosa than did NCs. The callosal regions most affected in AD included the midbody, isthmus and genu. The isthmus and midbody areas of the CC were positively correlated with cognitive performance and with superior temporal lobe volume in AD patients. The mid-sagittal area of the AC and the superior temporal volumes did not differ between AD patients and NCs. Conclusions: The study demonstrated that the regional morphology of the $\mathrm{CC}$ correlates with current cognitive status and temporal lobe atrophy in AD. As well, the lack of difference for the AC suggests that commissural atrophy in AD is regionally specific.
\end{abstract}

RÉSUMÉ: Corrélation de la morphologie régionale du corps calleux au volume du lobe temporal et à la performance cognitive dans la maladie d'Alzheimer: Introduction: Des études récentes ont rapporté une atrophie significative du corps calleux (CC) dans la maladie d'Alzheimer (MA). Cependant, nous ne savons pas si l'atrophie du CC est associée à des changements spécifiques du volume cortical dans la MA. De plus, on n'a jamais examiné s'il existait une atrophie des commissures extra-calleuses. Le but de cette étude était de quantifier l'atrophie au niveau de deux commissures cérébrales $\{\mathrm{le} \mathrm{CC}$ et la commissure antérieure $(\mathrm{CA})\}$, de corréler cette mesure à l'état cognitif et de relier la taille commissurale à des mesures indépendantes du volume du lobe temporal chez des patients atteints de MA. Méthodes: Un échantillon de patients atteints de la MA et de sujets contrôles appariés pour l'âge et le niveau d'éducation (CNs) ont subi une RMN et une évaluation de la fonction cognitive au moyen de l'échelle de la démence et du Mini-examen de l'état mental. Les zones sagittales médianes du CC et la CA ont été mesurées ainsi que le volume des lobes temporaux supérieurs, moyens et inférieurs. Résultats: Les patients atteints de la MA avaient une mesure du CC significativement plus petite que les CNs. Les régions du CC les plus atteintes dans la MA comprenaient la partie moyenne du corps, l'isthme et le genou. L'isthme et la région moyenne du CC étaient positivement corrélés à la performance cognitive et au volume du lobe temporal supérieur chez les patients atteints de la MA. La région sagittale moyenne de la CA et les volumes temporaux supérieurs n'étaient pas différents chez les patients atteints de la MA et les CNs. Conclusions: Cette étude démontre que la morphologie régionale du CC est corrélée à l'état cognitif et à l'atrophie du lobe temporal dans la MA. De plus, l'absence de différence au niveau de la CA suggère que l'atrophie commissurale dans la MA est spécifique à la région.

Can. J. Neurol. Sci. 2000; 27: 204-209

The corpus callosum (CC) is the largest interhemispheric commissure, containing some 200 million neurons ${ }^{1}$ integrating widespread areas of the neocortex of the left and right cerebral hemispheres. Because the $\mathrm{CC}$ preserves the anterior-posterior distribution of cortical neurons, ${ }^{2,3,4}$ quantification of callosal morphology may provide insight into the regional cortical topographic changes associated with normal aging and Alzheimer's Disease (AD).
From the Cognitive Neurology Unit, Department of Medicine and Research Program in Aging, Sunnybrook Women's College and Health Sciences Centre, University of Toronto, Toronto, Ontario (SEB, DCY), Gerontology Research Center, National Institute on Aging, Baltimore MD (SDM), Institute of Mathematics and Computer Science, Bulgarian Academy of Sciences (PS), Medical Imaging, SWCHSC and Department of Medical Biophysics, University of Toronto, Toronto, Ontario (MB). Received SePtember 9, 1999. ACCEPTED In FinAl FORM MAY 23, 2000. Reprint requests to: Sandra E. Black, Head, Division of Neurology, Cognitive Neurology Unit, Sunnybrook Women's College and Health Sciences Centre, Room A421-2075, Bayview Avenue, North York, Ontario M4N 3M5 Canada 
Alzheimer's disease is a dementia characterized pathologically by the presence of amyloid plaques, neurofibrillary tangles and neuronal loss. Histopathologic and functional neuroimaging studies have demonstrated that the regions most severely compromised in $\mathrm{AD}$ are the hippocampus, the posterior cingulate gyrus and the temporal, posterior parietal and prefrontal association cortices, with relative sparing of the occipital cortex, anterior temporal regions and primary sensory and motor cortices. $5,6,7$ The pyramidal cells in lamina III represent one of the principal cell layers affected in the neocortex. ${ }^{8}$ Because the axons of cortical pyramidal cells give rise to the corpus callosum, ${ }^{9}$ pyramidal degeneration would be expected to result in atrophy of the $\mathrm{CC}$ in a manner that corresponds to the regional pathophysiology of the disease process.

Recent studies have reported significant reductions in midsagittal CC size in AD. ${ }^{10-20}$ For example, Biegon et al ${ }^{2}$ found that $\mathrm{AD}$ was accompanied by a reduction in $\mathrm{CC}$ area in the genu and midbody regions, while Lyoo et $\mathrm{al}^{13}$ reported that, relative to age-matched controls, individuals with AD demonstrated significant atrophy of the midbody and posterior CC. Interestingly, Teipel et $\mathrm{al}^{17}$ reported significant rostral and splenial $\mathrm{CC}$ atrophy in $\mathrm{AD}$ patients and further noted that the degree of $\mathrm{CC}$ atrophy was correlated with cerebral glucose metabolism in the corresponding cortical regions (see also Yamauchi ${ }^{14}$ ). Janowsky et $\mathrm{al}^{15}$ found that the entire cross sectional area of the CC was significantly smaller in AD patients compared to samples of both healthy elderly and incipient dementia' control subjects. Moreover, they reported a positive correlation between CC area and cognitive status as assessed by the Mini Mental Status Examination (MMSE), suggesting that atrophy of the $\mathrm{CC}$ may be useful in tracking cognitive decline in AD. ${ }^{13-16}$

In the present study, $\mathrm{AD}$ patients and healthy elderly control subjects underwent magnetic resonance imaging (MRI). As well as investigating regional $\mathrm{CC}$ atrophy in $\mathrm{AD}$, this study quantified temporal lobe volume and administered cognitive status and dementia screening tests to these subjects in order to examine correlations between $\mathrm{CC}$ atrophy, cortical degeneration and cognitive performance in $\mathrm{AD}$. It was predicted that regional atrophy within the $\mathrm{CC}$ would reflect the known topographical selectivity of $\mathrm{AD}^{5-7}$ and that $\mathrm{CC}$ atrophy would correlate with cognitive measures. For example, atrophy of the isthmus should correlate with superior temporal lobe volumes, since it interconnects these regions as indicated in Figure 1. Moreover, because previous studies have not investigated the status of other commissural systems, the present study also examined the midsagittal area of the anterior commissure (AC) in AD patients and NCs. Because the AC houses fibres originating primarily in the most anterior portions of the temporal lobes, ${ }^{21,22}$ which are relatively spared in $\mathrm{AD},{ }^{5,23}$ it was predicted that there would be no difference between $\mathrm{AD}$ patients and controls in $\mathrm{AC}$ area.

\section{METHOD}

\section{Subjects}

Patients with probable AD were recruited from the Cognitive Neurology Clinic at Sunnybrook and Women's College Health Science Centre, University of Toronto (Toronto, Canada). The group consisted of 23 patients (10 males, 13 females) who met the National Institute of Neurologic and Communicative Disorders and Stroke and the Alzheimer's Disease and Related Disorders Association diagnostic criteria for probable AD. ${ }^{24}$ The mean age of AD patients was $69.1( \pm 1.9)$ years, and the mean years of education was $12.9( \pm 0.6)$.

Seventeen community-dwelling normal control subjects (NCs) (10 males, 7 females) were recruited from the Greater Toronto Area. They had no history of any neurologic or psychiatric disease and performed within normal limits on formal neuropsychological testing. Furthermore, MRI scans from all NCs were within normal limits for their age. Normal controls had an average of $13.2( \pm 0.6)$ years of education and a mean age of $71.9( \pm 1.0)$ years. NCs did not differ from AD patients in either age $[\mathrm{t}(38)=1.18, \mathrm{p}=.25]$ or years of education $[\mathrm{t}(38)=0.43, \mathrm{p}=.67]$ indicating that $\mathrm{AD}$ patients and controls were adequately matched on these variables.

Subjects underwent MRI and were administered the Mattis Dementia Rating Scale (DRS) ${ }^{25}$ and the MMSE. ${ }^{26}$ The mean delay between the date of MRI and the date of cognitive testing was 44.4 ( \pm 52.8$)$ days. MMSE data for one AD patient and DRS data for three $\mathrm{AD}$ patients were excluded from cognitive analyses because the date of cognitive testing deviated by more than six months from the date of MRI. All NCs scored above 129 on the DRS which is above the recommended cut-off for probable dementia. ${ }^{25}$ The mean score on the DRS for AD patients $(\mathrm{X}=$ $105.37 \pm 17.17)$ was significantly lower $[\mathrm{T}(34)=8.09, \mathrm{p}<.001]$ than the mean score for NCs $(X=139.76 \pm 3.58)$. The mean score on the MMSE for AD patients $(X=18.1, \pm 5.4)$ was significantly lower $[\mathrm{t}(37)=7.37, \mathrm{p}<.001]$ than the MMSE scores of the NCs $(X=28.2, \pm 1.8)$.

\section{Procedure}

\section{Magnetic resonance imaging}

MRI scans were performed on a $1.5 \mathrm{~T}$ General Electric Signa MR system. A T1-weighted 3-D volume technique (TR = $35 \mathrm{~ms}$; $\mathrm{TE}=5 \mathrm{~ms}$; flip angle $=35$ degrees; field of view $=22 \mathrm{~cm}$; matrix size $=192 \times 256$ ) was used to obtain 124 contiguous sagittal slices (1.2 mm thickness). MR images were processed on a Sun microcomputer workstation using ANALYZE computer software (Biomedical Imaging Resource) for 3-D volume reconstruction and measurement. It is important to note with respect to white matter disease, that the subjects in the AD and NC samples had minimal white matter changes well within normal limits for age.

\section{Corpus callosum and anterior commissure measurement}

The CC was isolated based on intensity thresholds and automatically traced using an automated technique. This program divided the $\mathrm{CC}$ in mid-sagittal view into six subdivisions designed to maintain the anterior-posterior distribution of cortical neurons through the $\mathrm{CC} .^{2,3,4}$ The $\mathrm{CC}$ was segmented based on criteria devised by Witelson (1989). ${ }^{4}$ The rostrum of the $\mathrm{CC}$ was included as part of the genu (see Figure 1). All CC measures were obtained blind with respect to the disease status of subjects.

The anterior commissure in mid-sagittal section represents the convergence of axons from cell bodies which reside primarily in the anterior temporal lobe. ${ }^{21,22}$ The AC was traced in mid-sagittal section using a hand tracing technique (See Figure 


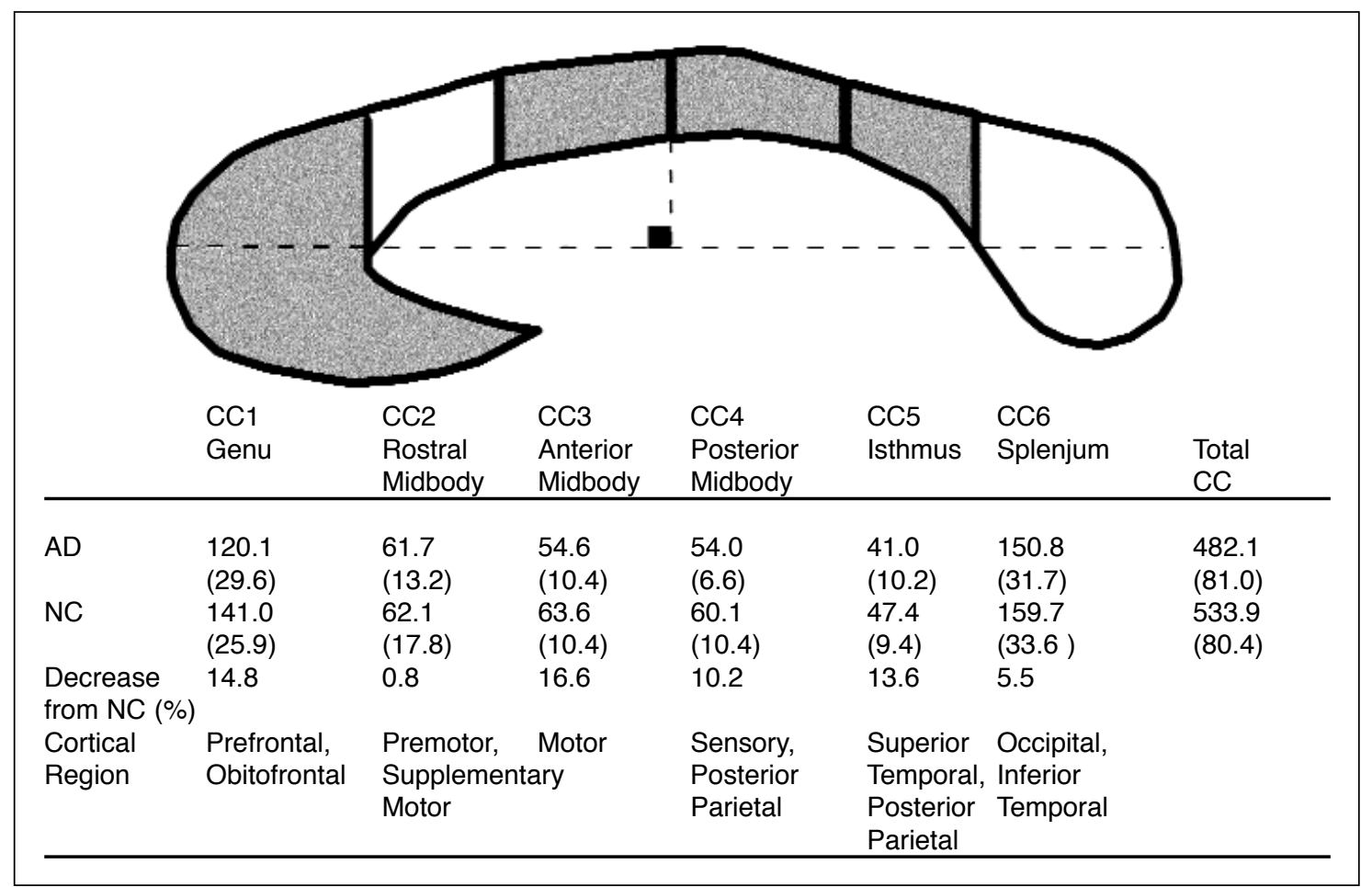

Figure 1: Regional callosal subdivisions and mean regional area measures (s.d.) in Alzheimer's Disease $(A D)$ patients and normal control subjects (NCs). Stippled areas reflect CC regions which were significantly smaller in $A D$ patients compared to those in NCs $(p<.05)$.

2). Under $3 X$ magnification, the experimenter traced the perimeter of the AC using a computer mouse, and the area of the AC was calculated by the ANALYZE software package. To establish that the area of this small structure could be traced reliably, the AC of each participant was traced at three separate times, twice by one of the experimenters (SM) and once by another independent rater (DY). All AC tracings were performed

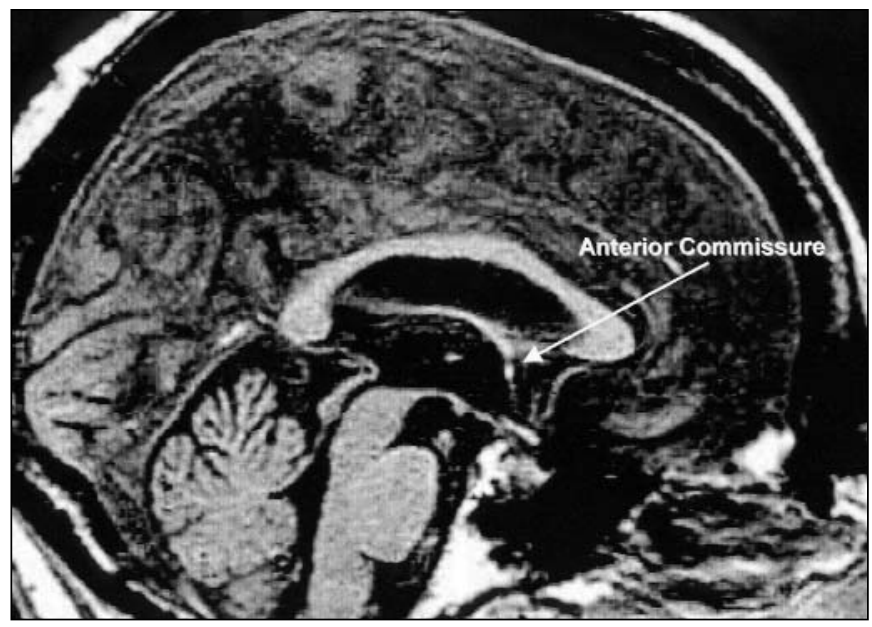

Figure 2: Mid-sagittal MRI showing the corpus callosum and anterior commissure (white arrow).

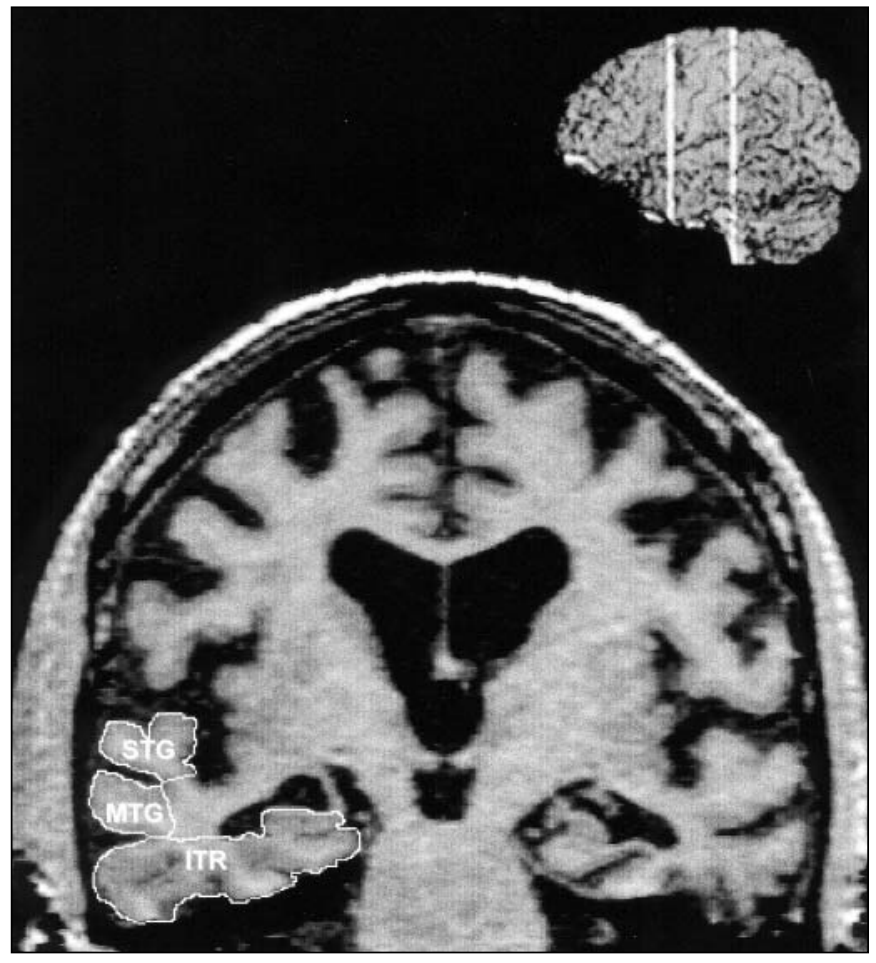

Figure 3: Coronal MRI depicting the regional demarcation of the superior temporal gyrus (STG), middle temporal gyrus (MTG) and inferior temporal region (ITR) in a representative AD patient. 
Table 1. Correlations of Region Callosal and Anterior Commissure Areas with Cognitive Test Performance in AD patients.

\begin{tabular}{lllllllll}
\hline & $\mathbf{C C 1}$ & $\mathbf{C C 2}$ & $\mathbf{C C 3}$ & $\mathbf{C C 4}$ & $\mathbf{C C 5}$ & CC6 & CC Total & AC \\
DRS & .44 & .29 & $.54 *$ & .43 & $.52^{*}$ & .12 & .39 & .31 \\
MMSE & .37 & -.07 & .31 & .31 & $.57 * *$ & .06 & .27 & .30 \\
\hline
\end{tabular}

$* \mathrm{p}<.05 . \quad * * \mathrm{p}<.01$

blind with respect to subject disease status and blind to the measurements obtained by other raters. Intraclass correlations revealed an intrarater reliability of $\mathrm{r}=.87$ and an interrater reliability of $r=.77$. Anterior commissure data from one subject was excluded due to movement artifact which obscured the structure in mid-sagittal section.

\section{Temporal lobe measures}

Portions of the superior temporal gyrus (STG), middle temporal gyrus (MTG) and inferior temporal region (ITR) (comprising inferior temporal gyrus, occipitotemporal gyrus, parahippocampal gyrus and hippocampus) were manually traced bilaterally over a series of six coronal slices. The coronal slices were perpendicular to the anterior commissure-posterior commissure axis from a sagittal point of view and perpendicular to the interhemispheric fissure from an axial view. Anatomical delineation of the STG, MTG and ITR was based on the neuroanatomic atlas of Talairach and Tournoux ${ }^{27}$ (see Figure 3). The first slice began at the AC and subsequent slices were posterior at $5.2 \mathrm{~mm}$ increments, thereby sampling the midtemporal region from the AC posteriorly for approximately 31 $\mathrm{mm}$. Following manual tracing of each of the six slices of each temporal region, the volume of each region was calculated according to Simpson's Law. ${ }^{28}$ The volume of the individual temporal lobe regions was based on the computation of the mean of the corresponding volumes for both the left and right hemispheres. A subset of 20 temporal lobe regions was measured twice by the same rater (DY) and once by a second blind rater (JP) to establish reliability of volume calculations. Intraclass correlations revealed that the intrarater reliability for all temporal lobe volumes was greater than $r=.93$. Interrater agreement for the STG was $r=.85$, for the MTG $r=.83$ and for the ITR $r=.76$.

\section{Intracranial capacity}

The total intracranial capacity was derived using a tissue

Table 2. Correlations of Regional Callosal and Anterior Commissure Areas with Temporal Lobe Volumes in AD patients.

\begin{tabular}{llllllll} 
& CC1 & CC2 & CC3 & CC4 & CC5 & CC6 & AC \\
STG & .35 & -.07 & $.43^{*}$ & .37 & $.61^{* *}$ & .13 & .39 \\
MTG & .34 & -.17 & .36 & .20 & .41 & .13 & .35 \\
ITR & .23 & -.37 & $.45^{*}$ & .18 & .37 & -.06 & .17 \\
\hline
\end{tabular}

$* \mathrm{p}<.05$.

$* * \mathrm{p}<.01$. classification technique to strip away nonbrain tissues as described previously. ${ }^{29}$ This gives an estimate of premorbid brain volume prior to any atrophic process, and allows any differences in head size to be taken into account in the group comparisons.

\section{Results}

The results of the area measurements for each subregion and overall areas are shown in Figure 1. To investigate the hypothesis that $\mathrm{AD}$ patients had smaller $\mathrm{CC}$ regions than NCs, analysis of variance (ANOVA) was performed comparing the two groups with respect to the regional subdivisions of the $\mathrm{CC}$. There was a main effect of disease status in which $\mathrm{AD}$ patients had significantly smaller callosal subregions in $\mathrm{CC} 1[\mathrm{~F}(1,38)=5.39$, $\mathrm{p}=.03], \mathrm{CC} 3[\mathrm{~F}(1,38)=7.44, \mathrm{p}=.01], \mathrm{CC} 4[\mathrm{~F}(1,38)=5.20, \mathrm{p}$ $=.03]$ and $\mathrm{CC} 5[\mathrm{~F}(1,38)=4.19, \mathrm{p}=.05]$. Overall, the total area of the $\mathrm{CC}$ was significantly smaller in AD patients than in NCs $[\mathrm{F}(1,38)=4.02, \mathrm{p}=.05]$. AD patients and NCs did not differ significantly in the area of regions $\mathrm{CC} 2[\mathrm{~F}(1,38)=0.01, \mathrm{p}=.92]$ or CC6 $[\mathrm{F}(1,38)=0.72, \mathrm{p}=.40]$ (see Figure 1$)$.

To investigate whether AD patients and NCs differed in AC area, an independent samples t-test was performed with disease status as independent variable and AC area as dependent measure. AD patients $\left(\mathrm{X}=6.84 \mathrm{~mm}^{2}, \pm 3.24\right)$ and $\mathrm{NCs}(\mathrm{X}=7.34$ $\left.\mathrm{mm}^{2}, \pm 2.29\right)$ did not differ significantly in the size of the AC $[\mathrm{t}(37)=0.54, \mathrm{p}=.59]$, suggesting some specificity of the group differences in the callosal subregions.

$\mathrm{AD}$ patients $(\mathrm{X}=1400.90, \pm 144.08)$ and controls $(\mathrm{X}=$ $1399.20, \pm 134.28$ ) did not differ in intracranial capacity which was used as an estimate of premorbid brain volume $[\mathrm{t}(38)=0.38$, $\mathrm{p}=.80]$.

To examine the degree to which regional callosal size indexed degree of cognitive decline in $\mathrm{AD}$, partial correlations were performed between regional $\mathrm{CC}$ area and performance on the DRS and MMSE within the AD patients. Age and years of education were incorporated as covariates to control for the possible confounding influence of these variables on cognitive performance. Scores on the DRS were significantly positively correlated with the area of region CC3 $[\mathrm{r}(15)=.54, \mathrm{p}=.03]$ and region CC5 $[\mathrm{r}(15)=.52, \mathrm{p}=.03]$. Scores on the MMSE were significantly positively correlated with the area of region CC5 $[\mathrm{r}(18)=.57, \mathrm{p}<.01]$. In contrast, the area of the $\mathrm{AC}$ was uncorrelated with performance on either the MMSE $[\mathrm{r}(17)=.30$, $\mathrm{p}=.21]$ or the DRS $[\mathrm{r}(14)=.31, \mathrm{p}=.24]$ (see Table 1$)$.

To compare $\mathrm{AD}$ patients and NCs in their temporal lobe volumes, ANOVA's were performed with disease status as independent variable and temporal lobe volumes as dependent variables. Because we did not observe significant temporal lobe asymmetries in this sample (all p's $>.05$ ), the mean of the left 
and right side were used as dependent variable for temporal lobe volume measures. Consistent with the pathophysiology of $\mathrm{AD}$, there was a main effect of disease status in which NCs had larger temporal lobe volumes for the ITR $[\mathrm{F}(1,38)=16.02, \mathrm{p}<.001]$ and MTG $[\mathrm{F}(1,38)=5.17, \mathrm{p}=.03]$. AD patients and NC's did not differ in the volume of the STG $[\mathrm{F}(1,38)=2.49, \mathrm{p}=.12]$.

To examine the degree to which regional callosal size indexed temporal lobe atrophy in $\mathrm{AD}$, correlations were performed examining the relationship between regional $\mathrm{CC}$ area and the volume of the STG, MTG and ITR within the AD patients (see Table 2). Given that the neurons of the STG are believed to pass through the isthmus of the $\mathrm{CC}, 3,4$ we predicted that the size of these structures would be correlated. Consistent with this topographical distribution of cortical projections through the $\mathrm{CC}$, significant correlations between STG volume and the isthmus (CC5) were observed $[\mathrm{r}(21)=.61, \mathrm{p}<.01]$. In addition, STG volume also correlated with the area of the anterior midbody $[\mathrm{r}(21)=.43, \mathrm{p}=.04]$ of the CC. No other significant correlations were observed and volumetric measures of this mid-temporal sample did not correlate significantly with AC area (see Table 2).

\section{DISCUSSION}

These results provide further evidence of significant CC atrophy in $\mathrm{AD}$ patients compared to healthy elderly control subjects. The mean total CC area in our AD sample $\left(482.1 \mathrm{~mm}^{2}\right)$ was similar to that reported in $\mathrm{AD}$ subjects by Biegon et al $\left(480 \mathrm{~mm}^{2}\right)^{12}$ and by Yamauchi et al $\left(469 \mathrm{~mm}^{2}\right) .{ }^{14}$ Our CC subdivisional areas also correspond closely to those reported by Lyoo et $\mathrm{al}^{13}$ who used the identical demarcation technique. ${ }^{4}$

Our data revealed significant atrophy throughout the midbody and isthmus of the $\mathrm{CC}$, callosal regions which interconnect central, posterior parietal and temporal cortices. ${ }^{2,4,30}$ Significant atrophy was also noted in genu of the $\mathrm{CC}$ which houses fibres originating primarily in prefrontal cortex. ${ }^{2,3,4}$ Although CC atrophy is known to occur as a function of normal aging, ${ }^{31,32}$ the significant differences between AD patients and NCs reported here and by others ${ }^{10-20}$ clearly demonstrate that the shrinkage in $\mathrm{CC}$ size in $\mathrm{AD}$ is out of proportion with that expected in normal aging. Moreover, our data demonstrated that $\mathrm{AC}$ area did not differ between $\mathrm{AD}$ patients and controls. As far as we are aware, this is the first study to investigate the effects of $\mathrm{AD}$ on a noncallosal commissural system. The lack of difference between $\mathrm{AD}$ and $\mathrm{NC}$ subjects in $\mathrm{AC}$ area supports the specificity of the atrophic changes to the cortical fibres which give rise to the $\mathrm{CC}$, and provides additional evidence that the $\mathrm{CC}$ shrinkage in $\mathrm{AD}$ has some cortical specificity and does not represent generalized commissural or white matter damage.

Although there are some reports of white matter abnormalities in $\mathrm{AD},{ }^{33}$ microscopic studies $^{5}$ and gross anatomical investigations ${ }^{29}$ reveal that grey matter structures are most affected. Moreover, Teipel et $\mathrm{al}^{18}$ and Hampel et al ${ }^{19}$ quantified regional callosal area and obtained measures of white matter hyperintensity load in $\mathrm{AD}$ patients and controls and reported that $\mathrm{CC}$ atrophy was independent of white matter hyperintensity ratings. The fact $\mathrm{AD}$ does not result in marked white matter damage, combined with the demonstrated independence of $\mathrm{CC}$ atrophy and ratings of MRI-determined white matter hyperintensities strongly suggests the $\mathrm{CC}$ atrophy reflects cortical neuronal degeneration rather than primary white matter pathology.

An interesting question regarding $\mathrm{CC}$ atrophy in $\mathrm{AD}$ is whether the examination of regional $\mathrm{CC}$ morphology may reflect specific topographic changes in the neocortex. In the present study, the most dramatic differences were observed in the midbody, isthmus and genu of the $\mathrm{CC}$. These findings mirror those obtained by Bigeon et $\mathrm{al}^{12}$ who also reported significant genu and midbody shrinkage in AD. Some studies, however, have observed reduction in $\mathrm{CC}$ size which is restricted to more posterior regions with a relative sparing of the anterior $\mathrm{CC},{ }^{14}$ while other studies have reported that the anterior CC may be primarily affected. ${ }^{15}$ Although the precise reason for disagreement between studies in the anatomical specificity of $\mathrm{CC}$ atrophy is not clear, marked differences in the operational divisions of the $\mathrm{CC}$ may play a prominent role. ${ }^{15}$ Disease heterogeneity and variations in the severity of the sample populations are also likely to be important factors. In particular, degenerative changes in the neocortex in $\mathrm{AD}$ are known to follow a temporal as well as topographic pattern, with posterior parietal, cingulate and temporal lobe damage preceding prefrontal involvement. ${ }^{34}$ It is possible that differences between studies in the regional specificity of the $\mathrm{CC}$ findings are related to differences in the temporal window through which individual studies have viewed the disease process. It will be important for future investigations to examine the possibility that regional atrophy of the $\mathrm{CC}$ is time-dependent, with some $\mathrm{CC}$ regions being more affected than others at different stages of the illness.

As well as reporting reduced regional callosal size in $\mathrm{AD}$, this study demonstrated that regional CC morphology correlates with cognitive status. In particular, the area of the isthmus of the $\mathrm{CC}$ was positively correlated with two independent measures of cognitive functioning in these patients. The present data suggest that regional $\mathrm{CC}$ morphology may reflect the severity of cognitive decline in AD.

Importantly, the identical callosal subregions which correlated with cognitive performance in $\mathrm{AD}$ also correlated with temporal lobe volume in our sample. This is precisely the callosal region identified by Thompson et $\mathrm{al}^{20}$ as demonstrating the most substantial areal loss in AD. These findings are consistent with the observation that parietal and temporal lobe regions, whose neurons give rise to the isthmus and posterior midbody of the $\mathrm{CC}$, are vulnerable in AD. However, it should be acknowledged, that significant correlations were also observed in CC3 (see Table 2). Although temporal lobe neurons are thought to project primarily through the posterior portion of the body of the $\mathrm{CC}$ in nonhuman primates, ${ }^{2}$ deLacoste et $\mathrm{al}^{3}$ have reported that in humans, some temporal lobe fibres may pass through the callosal midbody. Moreover, significant correlations with other callosal regions would not be unexpected if decreases in temporal lobe volume are indirectly indicative of degenerative changes in other cortical zones.

In summary, the present data provide additional support for the notion that $\mathrm{AD}$ is accompanied by regionally specific callosal atrophy which is out of proportion with that expected in normal aging. Moreover, this degeneration does not generalize to the $\mathrm{AC}$, a fibre tract which houses axons emanating from brain regions which are relatively spared in AD. Our findings combined with those of previous investigations suggest that AD 
may be associated with progressive hemispheric disconnection and demonstrate the utility of quantifying $\mathrm{CC}$ atrophy as a marker of regional neuronal degeneration and cognitive decline. Future studies which examine lobar/gyral volumes in a variety of cortical regions will elucidate the degree to which callosal measurement may chart the cortical topography and cognitive decline in $\mathrm{AD}$

\section{ACKNOWLEDGEMENTS}

Research reported in this article was supported by grants to Dr. S.E. Black by the Ontario Mental Health Foundation and the Medical Research Council of Canada.

\section{REFERENCES}

1. Tomasch J. Size, distribution, and number of fibres in the human corpus callosum. Anat Rec 1954; 119: 119-135.

2. Pandya DN, Seltzer B. The topography of commissural fibers. In: Lepor F, Ptito M, Jasper HH, eds. Two Hemispheres - One Brain: Functions of the Corpus Callosum. New York: Alan R Liss Inc, 1986: 47-73.

3. DeLacoste MC, Kirkpatrick JB, Ross ED. Topography of the human corpus callosum. J Neuropath Exp Neurol 1985: 44: 578-591.

4. Witelson SF. Hand and sex differences in the isthmus and genu of the human corpus callosum: a postmortem morphological study. Brain 1989; 112: 799-835.

5. Brun A, Gustafson L. Distribution of cerebral degeneration in Alzheimer's disease: a clinico-pathological study. Arch Psych Neurol Sci 1976; 223: 15-33.

6. Foster N, Chase TN, Mansi L, et al. Cortical abnormalities in Alzheimer's disease. Ann Neurol 1984; 16: 649-654.

7. Haxby JV, Grady CL, Koss E, et al. Longitudinal study of cerebral metabolic asymmetries and associated neuropsychological patterns in early dementia of the Alzheimer's type. Arch Neurol 1990; 47: 753-760.

8. Lewis DA, Campbell MJ, Terry RD, Morrison JH. Laminar and regional distributions of neurofibrillary tangles and neuritic plaques in Alzheimer's disease: a quantitative study of visual and auditory cortices. J Neurosci 1987; 7: 1799-1808.

9. Innocenti GM. What is so special about callosal connections? . In: Lepor F, Ptito M, Jasper HH, eds. Two Hemispheres - One Brain: Functions of the Corpus Callosum. New York: Alan R Liss Inc, 1986: 75-81.

10. Wiess S, Jellinger K, Wenger E. Morphometry of the corpus callosum in normal aging and Alzheimer's Disease. J Neural Transm 1991; 33:35-38.

11. Vermersch P, Scheltens P, Barkhom F, Steinling M, Leys D. Evidence for atrophy of the corpus callosum in Alzheimer's disease. Eur Neurol 1993; 34: 83-86.

12. Biegon A, Eberling JL, Richardson BC, et al. Human corpus callosum in aging and Alzheimer's disease: a magnetic resonance imaging study. Neurobiol Aging 1994; 15: 393-397.

13. Lyoo IK, Satlin A, Lee CK, Renshaw PF. Regional atrophy of the corpus callosum in subjects with Alzheimer's disease and multiinfarct dementia. Psych Res 1997; 74: 63-72.

14. Yamauchi H, Fukuyama H, Harada K, et al. Callosal atrophy parallels decreased cortical oxygen metabolism and neuropsychological impairment in Alzheimer's disease. Arch Neurol 1993; 50: 1070-1074.

15. Janowsky JS, Kaye JA, Carper RA. Atrophy of the corpus callosum in Alzheimer's disease versus healthy aging. J Amer Ger Soc
1996; 44: 798-803.

16. Kaufer DI, Miller BL, Itti L, et al. Midline cerebral morphometry distinguishes frontotemporal dementia and Alzheimer's disease. Neurology 1997; 48: 978-985.

17. Teipel SJ, Hampel H, Pietrini P, et al. Region-specific corpus callosum atrophy correlates with the regional pattern of cortical glucose metabolism in Alzheimer disease. Arch Neurol 1999; 56: 467-473.

18. Teipel SJ, Hampel H, Alexander GE, et al. Dissociation between corpus callosum atrophy and white matter pathology in Alzheimer's disease. Neurology 1998; 51: 1381-1385

19. Hampel H, Teipel SJ, Alexander GE, et al. Corpus callosum atrophy is a possible indicator of region- and cell type-specific neuronal degeneration in Alzheimer's disease. Arch Neurol 1998; 55: 193198.

20. Thompson PM, Moussai J, Zohoori S, et al. Cortical variability and asymmetry in normal aging and Alzheimer's disease. Cerebr Cortex 1998; 8: 492-509.

21. Jouanet ML, Gazzaniga MS. Cortical field origin of the anterior commissure of the rhesus monkey. Exp Neurol 1979; 66: 381397.

22. Pandya DN, Karol EA, Lele PP. The distribution of the anterior commissure in the squirrel monkey. Brain Res 1973; 49: 177180.

23. Brun A, Englund E. Regional pattern of degeneration in Alzheimer's disease: neuronal loss and histopathological grading. Histopathology 1981; 5: 549-564.

24. McKhann G, Drachman D, Folstein M, et al. Clinical diagnosis of Alzheimer's disease: report of the NINCDS-ARDA work group under the auspices of department of health and human services task force on Alzheimer's disease. Neurology 1984; 34: 939-944.

25. Mattis S. Mental status examination for organic mental syndrome in the elderly patient. In: Bellak L, Karasu TB, eds. Geriatric Psychiatry: A Handbook for Psychiatrists and Primary Care Physicians. New York: Grune \& Stratton, 1976: 77-121.

26. Folstein MF, Folstein SE, McHugh PR. "Mini-Mental State": a practical method for grading the cognitive state of patients for the clinician. J Psych Res 1975; 12: 189-198.

27. Talairach J, Tournoux P. Co-Planar Stereotaxic Atlas of the Human Brain-3- Dimensional Proportional System: An Approach to Cerebral Imaging. New York: Thieme Medical Publisher Inc., 1988.

28. Jack CR Jr, Gehring DG, Sharbrough FW, et al. Temporal lobe volume measurement from MR images: accuracy and left-right asymmetry in normal persons. J Comput Assist Tomogr 1988;12:21-29.

29. Kidron D, Black SE, Stanchev P, et al. Quantitative MR volumetry in Alzheimer's disease. Neurology 1997; 49: 1504-1512.

30. Seltzer B, Pandya DN. The distribution of posterior parietal fibres in the corpus callosum of the rhesus monkey. Exp Brain Res 1983; 49: 147-150.

31. Weiss S, Kimbacher M, Wenger E, Neuhold A. Morphometric analysis of the corpus callosum using MR: correlation of measurements with aging in healthy individuals. Am J Neuroradiol 1993; 14: 637-645.

32. Driesen NR, Raz N. The influence of sex, age and handedness on corpus callosum morphology: a meta-analysis. Psychobiology 1995; 23: 240-247.

33. Brun A, Englund E. A white matter disorder in dementia of the Alzheimer's type: a pathoanatomical study. Ann Neurol 1986; 8: 421-426.

34. Braak H, Braak E, Bohl J. Staging of Alzheimer-related cortical destruction. Eur Neurol 1993; 33: 403-408. 